3. The model is an adequate description of some experimental data which show apostatic selection.

4. The exactitude of fit of the model to the data suggests that there is not, as often thought, a high variance in the apostatic selection imposed by individual predators.

Acknowledgments.-We wish to thank Dr L. M. Cook for extensive discussions on this subject.

\title{
7. REFERENGES
}

ALLEN, J. A., AND CLARKE, B. 1968. Evidence for apostatic selection by wild passerines. Nature, 220, 501-502.

CLARKE, B. 1962. Balanced polymorphism and the diversity of sympatric species. In Taxonomy and Geography (ed. D. Nicholls), Syst. Ass. Publ. No. 4.

Cook, L. M. 1965. A note on apostasy. Heredity, 20,631-636.

PINNEY, D. J. 1964. Statistical methods in biological assay (2nd ed.). Griffin, London.

POPHAM, E. J. 1941. The variation in the colour of certain species of Arctocorisa (Hemiptera : Corixidae) and its significance. Proc. zool. Soc. Lond. A., III, 135-172.

TINBERGEN, L. 1960. The natural control of insects in pinewoods. I. Factors influencing the intensity of predation by songbirds. Arch. Neerl. Zool., 13, 265-336.

\section{ON THE POLYMORPHISM OF CYANOGENESIS IN LOTUS CORNICULATUS L.}

\section{SOME ASPECTS OF SELECTION}

DAVID A. JONES

Department of Genetics, University of Birmingham

Received 1.v.70

\section{INTRODUGTION}

BuBAR AND LAwSON (1959) have shown that different varieties, strains and ecotypes of Lotus corniculatus L. exhibit differences in their ability to survive winter conditions in Canada. Bubar (1964, personal communication) has indicated that he has no evidence to suggest that acyanogenic plants are either more or less subject to winter injury than cyanogenic plants. This report contains the results of a formal investigation of (1) the problem of winter survival, (2) the production of seed by plants of different phenotype, and (3) the reanalysis of some data presented by Dawson (1941) and by Daday (1954).

\section{Survival of mature plants}

During the early summer of 1966 clones were established from 42 plants of $L$. corniculatus. In late summer the plants were arranged in the experimental field using a randomised block, spaced plant design. The original plants were grown from seed and represented the four possible phenotypes with respect to cyanogenic glucosides and $\beta$-glucosidase production and in most cases each clone was represented by 6 replicates. A grand total of 242 experimental plants were used and these were derived from 15 which 
contained both glucosides and enzyme, 16 which contained neither, 6 had only the glucosides while 5 had only the enzyme. The limits on the smaller classes were imposed by the number of plants available for cloning. The original seed samples came from England and Wales on the one hand and from Denmark and Sweden on the other and the data have been partitioned as British/Scandinavian accordingly.

TABLE 1

Analysis of variance of survival of Lotus corniculatus

$\begin{array}{lrcc} & & \text { Survival of winter } & \text { Overall survival } \\ & \text { d.f. } & \text { M.S. } & 1966-68 \\ \text { Habitats } & 1 & 0 \cdot 371 & \text { M.S. } \\ \text { Phenotypes } & 3 & 0.431 & 23.656^{*} \\ \text { H } \times \text { P } & 3 & 0 \cdot 056 & 5 \cdot 484 \\ \text { Between plants } & 34 & 0.373 & 3 \cdot 228 \\ \text { Within clones } & 200 & 0.109 & 4.649 \\ \text { W } & & 0.024\end{array}$

The analysis is based on 242 plants. Forty-four plants died during the winter 1966-67, while 115 plants died during the period September 1966 to April 1968.

* Significant mean square at the 5 per cent. level for differences between habitats.

On several occasions during the winter of 1966-67 the plants were scored, but the deadline for winter survival was taken as 1st May. This date was chosen because no plant which was alive in March had died by Ist May and yet sufficient time in early summer was needed to ensure that dormant plants had adequate chance to produce shoots above ground. Nearly a dozen plants were in this category.

By 1 st May, 18.2 per cent. of the plants originally put in the field had died. By the following 9 th November a total of 42.5 per cent. of the plants had died while a further 5 per cent. died during the second winter.

TABLe 2

Pattern of survival of plants in relation to their source

$\begin{array}{lcccccc} & \text { Died between } & \text { Died between } & \text { Died between } & & & \\ & 14.9 .66 \text { and } & 1.5 .67 \text { and } & 9.11 .67 \text { and } & \text { Survived } & \\ & 1.5 .67 & 9.11 .67 & 23.4 .68 & \text { to } 23.4 .68 & \text { Total } \\ \text { British } & 23 & 16 & 4 & 78 & 121 \\ \text { Scandinavian } & 21 & 43 & 8 & 49 & 121 \\ \text { Total } & 44 & 59 & 12 & 127 & 242\end{array}$

Use was made of the scheme for disproportionate numbers in an $\mathrm{R} \times 2$ table outlined by Snedecor and Cochran (1967) in preparing the two-way analysis of variance presented in table 1 . There is no evidence of an effect of habitat or of phenotype on the ability of plants to survive the first winter. There is, however, a marked effect of the source of the plants on the overall survival from September 1966 through April 1968. Closer examination of the data (table 2) shows that 43 per cent. of the Scandinavian plants remaining in the spring of 1967 died during the following summer, while only 16.3 per cent. of the British plants failed to survive until November 1967. Phenotype, therefore, does not appear to influence the overall survival of the plants in Birmingham during the period 1966-68. 


\section{SEED PRODUCTION}

During 1967 all the seed produced by the plants used in the survival experiments were collected. Care was taken to ensure that the seed was ripe before harvesting so that errors due to the stimulation of succession flowering would be minimal. No restriction was placed on the source of pollen and ripe seed was collected weekly from June through October.

Plants varied in their seed output from zero to over 18,000 and the results were analysed by the same technique as the one used for survival. For computation the seed numbers were reduced by a factor of $10^{3}$ so this means that all the mean squares in table 3 should be multiplied by $10^{6}$ to give their true values. The adjustment of scale makes no difference to the variance ratio test.

\section{TABLE 3}

Analysis of variance of seed production by Lotus corniculatus

\begin{tabular}{|c|c|c|c|c|c|c|}
\hline & \multicolumn{2}{|c|}{$\begin{array}{l}\text { Plants which } \\
\text { produced seeds }\end{array}$} & \multicolumn{2}{|c|}{$\begin{array}{c}\text { Plants alive at the } \\
\text { end of the harvest } \\
\text { period }\end{array}$} & \multicolumn{2}{|c|}{ All plants } \\
\hline & d.f. & M.S. & d.f. & M.S. & d.f. & M.S. \\
\hline Habitats & 1 & $89 \cdot 319$ & 1 & 8.824 & 1 & 3.045 \\
\hline Phenotypes & 3 & $50 \cdot 742$ & 3 & $28 \cdot 334$ & 3 & $23 \cdot 450$ \\
\hline $\mathbf{H} \times \mathbf{P}$ & 3 & 13.955 & 3 & $16 \cdot 378$ & 3 & $14 \cdot 186$ \\
\hline Between plants & 27 & $36 \cdot 618$ & 32 & $38 \cdot 755$ & 34 & $38 \cdot 401$ \\
\hline Within clones & 97 & $5 \cdot 385$ & 133 & 5.053 & 200 & 4.575 \\
\hline
\end{tabular}

See the comment on scale in the text.

Clearly not all the plants used in the survival experiments were alive to produce seeds and even some of those which were alive throughout the harvesting period produced no seeds at all. This means that there are three ways in which the data can be grouped. Firstly, we may include only those plants which produced seeds; secondly, we can consider those plants which were alive during the harvesting period, whether they produced seeds or not; and thirdly, there is the overall seed production of all 242 plants used in the experiment.

The analysis of variance in table 3 reveals that the effect of difference between plants is greater than differences between habitats or phenotypes, and even when we consider only those plants which produced seeds the mean square for habitats, although large, is not significant. This evidence suggests that the cyanogenic phenotype and the source of the plant material has little effect on seed production in the conditions under which the plants were grown. It is noticeable how consistent are the mean squares for within clones and between plants, showing that the individuals which died early and those which did not produce seed were a random sample of all the plants.

\section{Developmental viability of Lotus corniculatus}

In his paper on the inheritance of cyanogenesis in L. corniculatus, Dawson (1941) has listed both the number of seeds sown and the number of seeds germinated in addition to the results of reciprocal crosses. The percentage germination was high (not less than 95 per cent.), but there was considerable 
mortality between germination and the age at which the plants were tested for cyanogenesis. This breeding data can be used, therefore, to examine whether there are any differences between the reciprocal crosses with respect to segregation at the glucoside locus during the maturation of the plants.

TABLE 4

A summary of the 13 crosses Aaaa $\times$ aaaa and their reciprocals (Data of Dawson, 1941)

$\begin{array}{lccccc} & \text { Dead } & \text { Scored } & & \text { Dead } & \text { Scored } \\ 5^{9} \times 5^{40} & 47 & 73 & 5^{45} \times 5^{40} & 11 & 69 \\ & 45 & 35 & & 13 & 67 \\ 4^{18} \times 5^{40} & 29 & 51 & 5^{28} \times 5^{17} & 9 & 71 \\ & 28 & 52 & & 10 & 70 \\ 5^{38} \times 5^{40} & 50 & 30 & 4^{28} \times 5^{40} & 13 & 27 \\ & 35 & 45 & & 7 & 33 \\ 4^{18} \times 5^{38} & 24 & 96 & 5^{38} \times 5^{40} & 12 & 28 \\ & 44 & 76 & & 23 & 17 \\ 5^{48} \times 5^{34} & 10 & 41 & 5^{1} \times 5^{18} & 17 & 23 \\ & 47 & 113 & & 11 & 29 \\ 4^{28} \times 4^{11} & 6 & 74 & 5^{21} \times 5^{18} & 5 & 35 \\ & 9 & 71 & & 9 & 31 \\ 4^{18} \times 4^{11} & 14 & 66 & & & \end{array}$

TABLE 5

$2 \times 2$ contingency $x^{2}$ analysis of reciprocal crosses between Aaaa and aaaa

$\begin{array}{lrrc} & \text { d.f. } & \chi^{2} & \\ \text { Between reciprocals } & 1 & 2.699 & 0.2>\text { P }>0.1 \\ \text { Between crosses } & 12 & 32.146 & 0.01>\text { P }>0.001\end{array}$

TABLE 6

The progeny of plant $5^{10}$ (aaaa) when used as seed and pollen parent in crosses with plants of Aaaa genotype

\begin{tabular}{|c|c|c|c|c|c|c|}
\hline \multirow{2}{*}{$\begin{array}{l}\text { Other } \\
\text { parent }\end{array}$} & \multicolumn{3}{|c|}{$540 \%$} & \multicolumn{3}{|c|}{$5^{40} \sigma^{\circ}$} \\
\hline & Dead & Tested & Total & Dead & Tested & Total \\
\hline $\begin{array}{l}5^{9} \\
4^{16} \\
5^{98} \\
5^{45} \\
4^{28} \\
5^{32}\end{array}$ & $\begin{array}{r}45 \\
28 \\
35 \\
13 \\
7 \\
23\end{array}$ & $\begin{array}{l}35 \\
52 \\
45 \\
67 \\
33 \\
17\end{array}$ & $\begin{array}{l}80 \\
80 \\
80 \\
80 \\
40 \\
40\end{array}$ & $\begin{array}{l}47 \\
29 \\
50 \\
11 \\
13 \\
12\end{array}$ & $\begin{array}{l}73 \\
51 \\
30 \\
69 \\
27 \\
28\end{array}$ & $\begin{array}{r}120 \\
80 \\
80 \\
80 \\
40 \\
40\end{array}$ \\
\hline \multirow[t]{2}{*}{ Total } & 151 & 249 & 400 & 162 & 278 & 440 \\
\hline & \multicolumn{3}{|c|}{ Heterogeneity $\begin{aligned} \chi_{5}^{2} & =42.49 \\
P & <0.001\end{aligned}$} & \multicolumn{3}{|c|}{ Heterogeneity $\begin{aligned} \chi_{8}^{2} & =42.40 \\
P & <0.001\end{aligned}$} \\
\hline
\end{tabular}

Table 4 is a summary of the 13 crosses Aaaa $\times$ aaaa and their reciprocals. When these reciprocal crosses and the pooled data are examined as $2 \times 2$ contingency tables the results listed in table 5 are obtained. Thus there is no significant departure from contingency in the pooled data, but the crosses 
are highly heterogeneous. Analysis of $\chi^{2}$ reveals that 4 of the 13 reciprocal crosses are significant. Thus in 9 of the crosses and their reciprocals there is no evidence of a consistent effect (either maternal or paternal) on survival to maturity. On the other hand, 4 matings do show a significant difference between the reciprocal crosses, but note that plant $5^{40}$ is the aaaa parent in three of these matings. The behaviour of this plant both as seed parent and pollen parent in the 6 crosses in which it was used was, however, also heterogeneous and so the progeny of plant $5^{40}$ did not behave in a rational way (see table 6).

TABLE 7

Analysis of $x^{2}$ for segregation of $\mathrm{A}$ from $\mathrm{a}$ in the reciprocal crosses Aaaa $\times$ aaaa

$\begin{array}{lccc} & \text { d.f. } & \chi^{2} & \\ \text { Between reciprocals } & 1 & 0.062 & P>0.80 \\ \text { Between crosses } & 12 & 8.460 & P>0.70\end{array}$

Furthermore, Dawson has shown that the overall data are not heterogeneous for the segregation expected from a cross Aaaa $\times a a a a$ (table 7), and therefore it can be concluded that the differential survival from seedling to maturity is unlikely to be associated with the character of cyanogenesis, when the plants are grown under experimental conditions.

\section{Seed samples from wild populations of Trifolium repens AND Lotus corniculatus}

Daday (1954) lists the phenotypes of $T$. repens plants grown from seed samples collected from various localities in Europe. This data has been reworked using angular transformation of the phenotype frequencies and not the supposed allele frequencies. The analysis of variance in table 8 reveals that the regression of the frequency of the enzymatic form on the glucosidic form is highly significant.

TABLE 8

Analysis of variance of regression of the frequency of the enzymatic form on the frequency of the glucosidic form of Trifolium repens. (Data of Daday, 1954)

\begin{tabular}{lrrr} 
& d.f. & \multicolumn{1}{c}{ M.S. } & \\
Regression & 1 & 18123.42 & $\mathrm{P}<0.001$ \\
Residual & 47 & 83.45 &
\end{tabular}

The reasons for using the phenotype frequencies will be discussed in the fourth paper of this series.

Similar data have now been obtained for Lotus corniculatus and they are presented in table 9 . A population was sampled by collecting one pod from each of at least 20 plants. All the seeds from one population were mixed together. Samples of these seeds were sown and the phenotype frequencies in the resultant plants were determined.

The analysis of variance of regression in table 10 again shows a highly significant correlation between the frequency of the two forms of Lotus corniculatus. There is no doubt, therefore, that the interaction between the 
enzyme and the glucosides is very similar in each species. The evidence also points to the production of $\mathrm{HCN}$ being an important function of the enzyme substrate system in both species.

TABLE 9

Phenotypic frequencies of plants of Lotus corniculatus grown from seeds collected in fourteen different locations

Britain

1 Aysgarth, Yorks

2 Llanidloes, Radnor

3 Rounds Green, Staffs.

4 Forest Hill, Oxon.

5 Blenheim Park, Oxon.

6 Long Hanborough, Oxon.

7 Newbury, Berks.

8 Denbies, Surrey

9 Kynance Cove, Cornwall
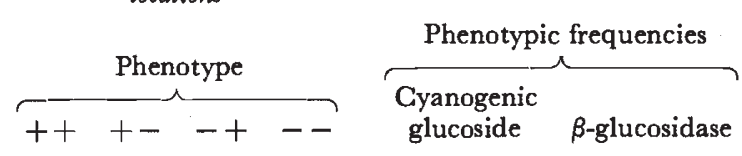

\section{Sweden}

10 Eskilstuna

11 Sannas

12 Halleviksstrand

13 Orust

$\begin{array}{rrr}93 & 2 & 1 \\ 32 & 50 & 6 \\ 112 & 3 & 1 \\ 28 & 6 & 1 \\ 36 & 19 & 11 \\ 38 & 18 & 0 \\ 86 & 5 & 1 \\ 27 & 1 & 2 \\ 28 & 8 & 14\end{array}$

$\begin{array}{rll}0 & 0.9895 & 0.9792 \\ 20 & 0.7592 & 0.3519 \\ 1 & 0.9829 & 0.9658 \\ 1 & 0.9444 & 0 \cdot 8056 \\ 16 & 0.6707 & 0.5732 \\ 0 & 1.0000 & 0.6786 \\ 0 & 0.9891 & 0.9457 \\ 0 & 0.9333 & 0.9667 \\ 3 & 0.6792 & 0.7924\end{array}$

\section{Denmark}

14 Ábenrå

$\begin{array}{rrrr}92 & 5 & 32 & 7 \\ 0 & 0 & 6 & 43 \\ 2 & 17 & 8 & 192 \\ 0 & 0 & 5 & 62\end{array}$

$\begin{array}{ll}0.7132 & 0.9118 \\ 0.0000 & 0.1224 \\ 0.0868 & 0.0457 \\ 0.0000 & 0.0746\end{array}$

++ glucoside and enzyme; + + glucoside, no enzyme; -+ enzyme, no glucoside; - - neither glucoside nor enzyme. Percentage germination in excess of 95 per cent.

\section{TABLE 10}

Analysis of variance of regression of the frequency of the enzymatic form on the frequency of the glucosidic form of Lotus corniculatus

$\begin{array}{lrrc} & \text { d.f. } & \text { M.S. } & \\ \text { Regression } & 1 & 6914.73 & \mathrm{P}<0.001 \\ \text { Residual } & 12 & 158 \cdot 12 & -\end{array}$

Data in table 9.

\section{Discussion}

Cyanogenesis in Trifolium repens and Lotus corniculatus is determined by the action of a $\beta$-glucosidase on two cyanogenic glucosides, linamarin and lotaustralin. It appears that the biochemical systems are very similar in the two species (Butler, 1965), but study of the enzymes is still at an early stage (Hughes, 1968). Evidence has been presented by Jones (1966) that the selective eating of the acyanogenic form of $L$. corniculatus by certain molluscs is likely to be important in the dynamics of the polymorphism and he suggested that selective eating might be important in $T$. repens also. On the other hand, Bishop and Korn (1969) obtained no evidence of selective 
eating of $T$. repens by Agriolimax reticulatus Müller and Helix aspersa Müller in their elegant experiments even though mention has been made on several occasions that selective eating may be important in this species (Corkill, 1952; Daday, 1955; W. Ellis Davies, 1967, personal communication).

Previously, Daday (1965) was able to demonstrate by direct experimentation that the acyanogenic form of $T$. repens was at a selective disadvantage in a coastal environment in New South Wales (January mean temperature $22^{\circ} \mathrm{C}$., July mean temperature $13^{\circ} \mathrm{C}$.) whereas the cyanogenic form was a disadvantage in an alpine environment in N.S.W. where the January mean temperature is $12^{\circ} \mathrm{C}$. and the July mean temperature $-2^{\circ} \mathrm{C}$. He suggests that it is not the cyanogenic character per se which is responsible for the advantage of such plants at high winter mean temperature, but that the locus concerned with cyanogenic glucoside production is genetically linked to genes concerned with fitness responses to temperature. His evidence, that plants which contain cyanogenic glucosides but no enzyme (phenotypically acyanogenic) are as fit as acyanogenic plants, supports this hypothesis. Obviously the suggestion could be proved or disproved quite simply by the appropriate breeding programme.

The work reported earlier in this paper suggests that the cyanogenic phenotype has little or no effect on survival by $L$. corniculatus of either winter or summer conditions in England.

On the surface, therefore, it appears that the selective agents are different in the two species and yet the polymorphisms of cyanogenesis are essentially the same. This is not to say that selective eating of $T$. repens and effects of temperature on $L$. corniculatus are always unimportant; it merely indicates that these selective agents are relatively trivial in the experiments which have been carried out so far.

If winter temperature is the sole or major selective agent in T. repens it is difficult to understand why the populations remain polymorphic. It is more likely that the selection is cyclical. For example, in habitats where the mean temperature is high in summer cyanogenic plants have an advantage because of physiological superiority and perhaps lack of predation. In winter, on the other hand, the acyanogenic form may be at an advantage because of frost resistance. In regions where the summer temperature is low, the selective advantage associated with the cyanogenic form could well be lower than in the warmer regions and so the net effect of the cyclical selection may favour the acyanogenic forms.

From the evidence presented earlier this explanation is unlikely to hold for L. corniculatus. Survival of winter and summer does not apparently depend upon the cyanogenic phenotype nor yet on genes genetically linked to the glucoside locus. In the fourth paper of this series (Jones, in preparation) evidence will be presented showing that the distribution of the cyanogenic forms of $L$. corniculatus in Europe does not parallel that of $T$. repens, although there are similarities. This result also suggests that winter temperature is of much less importance in determining the distribution of the cyanogenic form of $L$. corniculatus.

The apparent paradox in the response of the various cyanogenic and acyanogenic forms of the two species to selection by temperature is, therefore, simply resolved. In $L$. corniculatus, the genes concerned with temperature response are not genetically linked to the glucoside locus while in $T$. repens they are. In $T$. repens there is, consequently, a correlated response of the 
glucoside locus to selection and this is reflected in the frequency distribution of the cyanogenic form. Why there should be this difference in genetic architecture between the two species is a problem which requires further investigation. Whatever explanation there is for these differences it must also accommodate the interactions between the species which were reported previously (Jones, 1968).

As far as the selective eating of the acyanogenic form of $L$. corniculatus is concerned it is now necessary to determine the distribution and abundance of molluscs in relation to the distribution of cyanogenic plants. This should reveal whether selective eating is important or trivial in natural populations. Further population studies and selection experiments are in progress.

In both $T$. repens and $L$. corniculatus there is a high correlation between the frequency of plants containing the cyanogenic glucosides and the frequency of plants containing the $\beta$-glucosidase. HCN is not evolved by plants containing both the glucosides and the enzyme unless the plant is damaged, in which case the production of HCN begins immediately (Corkill, 1942). There can be little doubt, therefore, that the production of $\mathrm{HCN}$ is a response to plant damage and the $\mathrm{HCN}$, being highly toxic, could be a device for preventing further damage by grazing animals. This does not in any way rule out the probability that individuals or species may be partly or wholly resistant to $\mathrm{HCN}$ in the quantities evolved by these plants.

\section{SUMMARY}

1. The character of cyanogenesis appears to play little or no part in determining whether mature Lotus corniculatus plants survive either winter or summer conditions.

2. Scandinavian plants appear to be less suited to summer conditions in England than do British plants.

3. There is no difference between cyanogenic and acyanogenic plants in their ability to survive from seed to maturity under horticultural management.

4. A strong correlation between the frequency of the allele determining cyanogenic glucosides and the allele determining the $\beta$-glucosidase has been demonstrated for populations of Lotus corniculatus.

5. The role of temperature in the maintenance of the polymorphism of cyanogenesis in Trifolium repens and Lotus corniculatus is discussed and an explanation of the differences observed is suggested.

Acknowledgments.-I am most grateful to Professor J. L. Jinks, F.R.S., for his constructive comments during the course of this work. The Decca seed counter supplied by the Science Research Council to Dr M. J. Lawrence was used for counting the seeds of Lotus corniculatus. I am greatly indebted to the Science Research Council for financial support.

\section{REFERENCES}

BtsHop, J. A., AND KORN, M. E. 1969. Natural selection and cyanogenesis in white clover, Trifolium repens $\mathrm{L}$. Heredity, 24, 423-430.

BUbAR, J. s., AND LAWSON, N. C. 1959. Note on inheritance of ability to survive winterkilling conditions in Birdsfoot Trefoil. Canad. J. Pl. Sci., 39, 125-126.

BUTLER, G. W. 1965. The distribution of the cyanoglucosides linamarin or lotaustralin in higher plants. Phytochemistry, 4, 127-131.

Corxill, L. 1942. Cyanogenesis in white clover (Trifolium repens L.). V. The inheritance of cyanogenesis. N.Z. J. Sci. Tech., 23 B, 178-193. 
CORKILL, L. 1952. Cyanogenesis in white clover (Trifolium repens L.). VI. Experiments with high glucoside and glucoside free strains. N.Z. F. Sci. Tech., 34A, 1-16.

DADAY, H. 1954. Gene frequencies in wild populations of Trifolium repens L. 1. Distribution by latitude. Heredity, 8, 61-78.

DADAY, H. 1955. Cyanogenesis in strains of white clover (Trifolium repens L.). F. Brit. Grassland Soc., 10, 266-274.

DADAY, H. 1965. Gene frequencies in wild populations of Trifolizm repens L. IV. Mechanism of natural selection. Heredity, 20, 355-365.

DAWson, G. D. R. 1941. Tetrasomic inheritance in Lotus corniculatus L. F. Genetics, 42, 49-72. HUGHEs, M. A. 1968. Studies on the $\beta$-glucosidase system of Trifolium repens L. F. Exp. Bot., $19,427-434$.

JONEs, D. A. 1966. On the polymorphism of cyanogenesis in Lotus corniculatus L. Selection by animals. Canad. 7. Genet. Cytol., 8, 556-567.

JONEs, D. A. 1968. On the polymorphism of cyanogenesis in Lotus corniculatus L. II. The interaction with Trifolium repens $\mathrm{L}$. Heredity, 23, 453-455.

SNEDECOR, G. W., AND COCHRAN, w. G. 1967. Statistical Methods. 6th Edition, Iowa State University Press, Ames.

\title{
LIGHT AND TEMPERATURE EFFECTS ON THE GERMINATION OF WILD OATS
}

\author{
W. J. WHITTINGTON, J. HILLMAN, S. M. GATENBY, B. E. HOOPER \\ and J. C. WHITE \\ University of Nottingham School of Agriculture, Sutton Bonington, \\ Loughborough, Leicestershire
}

Received 6.v.70

\section{INTRODUCTION}

Avena fatua L. and Avena ludoviciana Dur. are the wild oats of English agriculture. A. ludoviciana tends to occur on heavy land where winter cereals are grown, and the caryopses (seed or grain) of this species germinate mainly in autumn. A. fatua, on the other hand, has a wider distribution and is particularly associated with spring cereals (Thurston, 1954); the grain of this species show some germination in autumn but a considerably greater frequency of germination occurs in spring (Thurston, 1951). Reports indicate considerable variation in the degree and periodicity of dormancy both between and within samples of $A$. fatua from different localities (Toole and Coffman, 1940; Sexsmith, 1967).

The genetic control of dormancy in oats has been considered by Garber and Quisenberry (1923), who found that delayed germination was recessive in crosses involving $A$. fatua and $A$. sativa. Johnson (1935b), using similar material, suggested that the observed variation could be explained on a three-locus basis in which the triple recessive genotype showed greatest dormancy.

Purely genetic models invoked to explain germination characteristics ignore the very marked effects of environmental factors during grain development. Thus, both the position in the spikelet at which the seed develops and the storage conditions markedly affect germination behaviour (Johnson, 1935a; Kommedahl, DeVay and Christensen, 1958; Thurston, 1963a). Environmental effects also cause variation during germination (Black and Naylor, 1957). Cumming and Hay (1958) found an inhibitory effect of 